Pak. j. sci. ind. res. Ser. A: phys. sci. 2019 62A(2) 82-91

\title{
Physicochemical Characterization and FTIR Spectroscopic Study of Pectin from Bombax ceiba (Bamta) Fruit
}

\author{
Ibrahim Iliya Nkafamiya ${ }^{a}$, Eneche Edogbo Jude ${ }^{a *}$, Dimas Blessed Jen ${ }^{b}$ and Isaac Ernest ${ }^{c}$ \\ ${ }^{a}$ Department of Chemistry, Modibbo Adama University of Technology, Yola, P.M.B. 2076, \\ Adamawa State, Nigeria \\ ${ }^{b}$ Department of Science Education, Taraba State University, Jalingo, Taraba State, Nigeria \\ 'Department of Chemistry, Taraba State University, Jalingo, Taraba State, Nigeria
}

(received September 12, 2018; revised December 6, 2018; accepted December 11, 2018)

\begin{abstract}
Pectin is a naturally occurring biopolymer which can be used for food and pharmaceutical applications. In this study the effect of temperature, time and $\mathrm{pH}$ on the yield, physicochemical characteristics of pectin extracted from Bombax ceiba fruits was investigated. The extraction of pectin was done using citric acid buffer followed by $96 \%$ alcohol precipitation. The optimum temperature, time and $\mathrm{pH}$ for the extraction of pectin were determined to be $85^{\circ} \mathrm{C}, 90 \mathrm{~min}$ and 2.0 , respectively. The yield of pectin under these optimum conditions was found to be $16.35 \%$. The physicochemical properties determined under these optimum conditions were found to be; equivalent weight; $765.40 \mathrm{mg} / \mathrm{mol}$, methoxyl content: $6.62 \%$, anhydrouronic acid content; $65.25 \%$, degree of esterification; $72.45 \%$, moisture content; $1.30 \%$ and ash content; $0.60 \%$ for Bombax ceiba fruits extracted pectin, respectively. FTIR was also utilized for characterizing the pectins. Generally, the findings of the study showed that the pectin extracted from Bombax ceiba fruit can find industrial applications, especially in food processing and pharmaceutical industries.
\end{abstract}

Keywords: pectin, Bombax ceiba, yield, acid extraction, FTIR, citric acid buffer

\section{Introduction}

Pectins are structural hetero-polysaccharide hydrocolloids contained mainly in the primary cell walls of many plants. It is also a multifunctional food ingredient that is widely used as gelling agent and mostly as stabilizers in food processing industries (Srivastava and Rishabha, 2011). Pectin is produced commercially in form of white to light brown powder, mainly extracted from citrus fruits as it is contained in the literature. The traditional application of pectin is as a gelling agent in jams and jellies, but over the past few years pectin has been increasingly used in new applications, not only in the food industry, but also in the pharmaceutical industry. Desai (2005); Liu et al. (2002), reported that several properties of pectin, such as gelling emulsifying, and film forming abilities, in addition to its resistance to degradation in the upper gastrointestinal tract, has allowed the continuous use of pectin in the development of drug delivery systems through encapsulation. Following the same rationale, pectin has the potential to be used in the encapsulation of unstable food ingredients.

*Author for correspondence;

E-mail: edogboeneche@gmail.com
According to Sriamornsak, (2003), the amount, structure and chemical composition of pectin differs between plants and within plants over time and in different parts of a particular plant. The pectin in fruit part of the plant is broken down into parts during ripening by the enzymes called pectinase and pectin esterase, making the fruit to become softer. The highest concentration of pectin can be found in the middle lamella of the cell wall with a gradual decrease when moving from the primary cell wall toward the plasma membrane. Despite the fact that pectin occurs commonly in most of the plant tissues, the commercial source of pectin is limited; this is because the ability of pectin to form gel depends on the molecular size and the degree of esterification. The pectin obtained from different sources differ in their gelling ability due to variation in certain parameters such as temperature and pressure during extraction.

In medicine, pectin increases viscosity and volume of stool so that it is used against constipation and diarrhoea. It has also been used in gentle heavy metal removal from biological systems. In ruminant nutrition, it depends on the extent of lignin cations of the cell wall; pectin is up to $90 \%$ digestible by bacterial enzymes. The ruminant nutritionists recommend that the digestibility of energy concentration in forage can be improved by 
increasing pectin concentration in the forage (Jafar and Gisoo, 2012).

Extraction is the most important process in the pectin production. Pectin extraction in a hot diluted strong mineral acid solution is the most commonly used method. Strong acids are corrosive and may be a potential threat to health. Moreover, the liquid waste generated from the industrial processes might lead to burden on the environment and a high cost might incur for treating the strong acidic waste (Lúcia et al., 2012). The extraction of pectin from fruit peels using weak organic acid such as citric acid has been intensively conducted in recent studies (Minjares-Fuentes et al., 2014; Kulkarni et al., 2010; Pinheiro et al., 2008). The aim of this work is to extract and characterize pectin from Bombax ceiba fruit using citric acid buffer at various $\mathrm{pH}$ and time for potential industrial applications.

\section{Materials and Methods}

Pectin extraction process. The fruits of Bombax ceiba (Bamta) was collected locally and at random from Girei Local Government Area market, Adamawa State, Nigeria. It was transported to Chemistry Laboratory in Modibbo Adama University of Technology Yola, Adamawa State, Nigeria. The samples were dried under shade for about seven days and then in an oven at a temperature of $105^{\circ} \mathrm{C}$ for about $6-8 \mathrm{~h}$ to reduce moisture content in the fruits. The dried sample was then crushed using mortar and pestle, and sieved using $63 \mu \mathrm{m}$ sieve into fine powdered form which were kept in desiccators at room temperature in the laboratory and small portions were taken for pectin extraction at batches. The extraction of the pectin hydrocolloids was carried out following standard methods (Tang et al., 2011; Menon et al., 2011; Srivastava et al., 2010) highlighted as follows: the dried prepared powdered or wet crushed sample (50 g) was weighed and blended with $300 \mathrm{~cm}^{3}$ buffer prepared from disodium hydrogen phosphate and citric acid to maintain the $\mathrm{pH}$ at 2.0 for both dry and wet sample extraction.

The acidified mixture of the blended sample was heated at 70,85 and $105^{\circ} \mathrm{C}$ for 45,60 and 90 min using a water bath and a stopwatch. After the heating period was over, the mixture was passed through four-fold muslin cloth twice and the extracts were allowed to cool to room temperature $\left(25^{\circ} \mathrm{C}\right)$ in order to minimize heat degradation of the pectin.
The extraction of pectin hydrocolloids was achieved using precipitation method with ethanol. The pectin extracts were concentrated and then precipitated in $96 \%$ ethanol. One volume of extracts was added to various volumes of ethanol at the sample fruit extracts and ethanol ratios (ER) of 1:2 and was agitated continuously for $10 \mathrm{~min}$. The mixture was kept aside for $2 \mathrm{~h}$ without stirring to allow the pectin to float on the surface. The pectin which was floating was filtered through four layered muslin cloth. The precipitates were washed three (3) times with $65 \%$ ethanol, and followed by $96 \%$ ethanol once to further remove any remaining impurity (Khule et al., 2012). Finally, the precipitate (i.e. the resulting pectin hydrocolloids) obtained was dried at $40{ }^{\circ} \mathrm{C}$ in the hot air circulating oven for two hours. The dried pectin was allowed to cool for about $24 \mathrm{~h}$ and further reduced into smaller size with a mortar and pestle and then weighed using an analytical balance. The percentage yield of pectin from the initial weight of sample was calculated. The dried pectin hydrocolloids extracts obtained were stored in desiccators until further use. The percentage yield of the extracted pectin hydrocolloids was calculated using the following equation:

$$
Y_{\text {pec }}(\%)=\frac{P}{Q} \times 100
$$

where:

$\mathrm{Y}_{\text {pec }}(\%)$ is the extracted pectin yield in percent (\%), $\mathrm{P}$ is the amount of extracted pectin in grams $(\mathrm{g})$ and $\mathrm{Q}$ is the initial amount of powder fruit samples $(50 \mathrm{~g})$.

Physicochemical characterization of pectin. The dried pectin samples obtained from the fruits were subjected to quantitative and qualitative test in order to determine its physicochemical characteristics. From the obtained results, the optimal conditions that will give the optimum yield were used for subsequent analysis.

Qualitative test. Colour. This was done by visual observation.

Solubility of dry pectin in cold and hot water. About $0.25 \%$ of the pectin samples was placed differently in a conical flask with $10 \mathrm{~mL}$ of $95 \%$ ethanol added followed by $50 \mathrm{~mL}$ distilled water. The mixture was shaken vigorously to form a suspension which was heated at $85{ }^{\circ} \mathrm{C}$ for $15 \mathrm{~min}$ (Yang et al., 2009).

Solubility of pectin solution in cold and hot alkali (NaOH). About $1 \mathrm{~mL}$ of $0.1 \mathrm{M} \mathrm{NaOH}$ was added to $5 \mathrm{~mL}$ pectin solution and then heated at $85^{\circ} \mathrm{C}$ for 15 $\min$ (Joslyn, 1980). 
pH determination. The choice of the $\mathrm{pH}$ was made by preparing a buffer at $\mathrm{pH} 7.0$ and the temperature was adjusted to $28^{\circ} \mathrm{C}$, the glass electrode was standardized with standard buffer solution. The electrode was rinsed with distilled water before inserting into the pectin solution and $\mathrm{pH}$ was determined using the $\mathrm{pH}$ meter.

Determination of ash and moisture contents. The moisture and ash content was determined by adopting (AOAC, 1995) method. As explained below:

Ash Content. The ash content of the extracted pectin samples was determined by weighing $1.0 \mathrm{~g}$ of pectin in a tarred crucible and then heated in a muffle furnace at $550{ }^{\circ} \mathrm{C}$ for four hours. The residue was cooled in a desiccator and weighed to a constant weight for three times. The percentage ash content of the sample was calculated using the expression below:

$$
\text { Ash content }(\%)=\frac{\text { Weight of the ash }(\mathrm{g})}{\text { Weight of pectin }(\mathrm{g})} \times 100
$$

Moisture contents. The moisture content of the pectin samples was determined by weighing $2.0 \mathrm{~g}$ of the sample into a well-dried crucible that was heated in an oven and cooled in a desiccator thereafter. The crucible and sample was heated in an oven set at $105^{\circ} \mathrm{C}$, which was removed and cooled in a desiccator and weighed. The process was repeated until a constant weight was obtained for all the samples. The moisture content was calculated from the expression given below:

$$
\text { Moisture content }(\%)=\frac{\text { Weight of the residue }(\mathrm{g})}{\text { Weight of pectin }(\mathrm{g})} \times 100
$$

Determination of equivalent weight. The determination of equivalent weight was carried out according to the method described by Ania et al. (2012) with some little modifications. The values of equivalent weights were used for calculating the anhydrouronic acid (AUA) content and the degree of esterification. Equivalent weights were determined by weighing $0.5 \mathrm{~g}$ pectin for each sample and placed into a $250 \mathrm{~mL}$ conical flask and moistened with $5 \mathrm{~mL}$ of ethanol. One gram of sodium chloride was introduced into the solution to sharpen its end point. Followed by $100 \mathrm{~mL}$ of distilled water and six drops of phenol red indicator that was freshly prepared, the mixture was stirred gently and then rapidly to ensure the dissolution of all pectin substance and no lumps retained on the sides of the flask before titrating.
Titration was done slowly (to avoid possible de-esterification) with $0.1 \mathrm{M}$ standardized $\mathrm{NaOH}$ to a pink colour change at the endpoint which is observed to be persistent for about $30 \mathrm{sec}$ and the volume of the alkali required for the complete neutralization was taken and recorded. The neutralized solution was utilized for the methoxyl content determination. The process was carried out for all samples at a duplicate. The following equation was used to calculate the equivalent weight of the pectin after titration:

$$
\begin{aligned}
& \text { Weight of the pectin } \\
& \text { Equivalent weight }(\mathrm{mg} / \mathrm{mol})=\frac{\text { sample }(\mathrm{g})}{\begin{array}{l}
\text { Volume of alkali } \\
\left(\mathrm{cm}^{3}\right) \times \text { Molarity } \\
\text { of alkali (M) }
\end{array}} \times 100
\end{aligned}
$$

Methoxyl content analysis of extracted pectin. The $\mathrm{MeO}$ content in a pectin sample is an important factor in controlling the setting time of pectin, the sensitivity to polyvalent cations and their functions in the preparation of low solid gels and fibers therefore, it is very necessary to be determined. The determination of the methoxyl $(\mathrm{MeO})$ content of the pectin sample was carried out by adding $25 \mathrm{~mL}$ of $0.25 \mathrm{M} \mathrm{NaOH}$ to the neutralized solution that was utilized for equivalent weight determination, which was shaken thoroughly, and allowed to stand for $30 \mathrm{~min}$ at room temperature in a stoppered flask. This was followed by the addition of $25 \mathrm{~mL}$ of $0.25 \mathrm{M} \mathrm{HCI}$ and titrated (Ania et al., 2012). The volume of the alkali required for the neutralization reaction was recorded and the methoxyl $(\mathrm{MeO})$ content was calculated from the expression given below:

$$
\begin{gathered}
\begin{array}{c}
\text { Volume of alklail }\left(\mathrm{cm}^{3}\right) \times \\
\text { Molarity of } \mathrm{NaOH}(\mathrm{g})
\end{array} \\
\text { Methoxyl content }(\%)=\frac{\begin{array}{l}
\text { Weight of pectin } \\
\text { sample }(\mathrm{mg}) \times 1000
\end{array}}{31 \times 100}
\end{gathered}
$$

where:

31 is the molecular weight of methoxyl $\left(\mathrm{CH}_{3} \mathrm{O}\right)$

Anhydrouronic acid (AUA) analysis of extracted pectin. The anhydrouronic acid (AUA) analysis was done by using the values of the equivalent weight and the methoxyl content obtained following the method specified by Ania et al. (2012). Thus, the anhydrouronic acid (AUA) content was calculated from the expression given below:

$$
\% \mathrm{AUA}=\frac{176 \times 0.1 \mathrm{z} \times 100}{\mathrm{~W} \times 1000}+\frac{176 \times 0.1 \mathrm{y} \times 100}{\mathrm{~W} \times 1000}
$$


where:

Molecular unit of AUA ( 1 unit $)=176 \mathrm{~g}, \mathrm{z}=$ volume $\mathrm{cm}^{3}$ (titre) of $\mathrm{NaOH}$ from equivalent weight determination, $\mathrm{y}=$ volume $\mathrm{cm}^{3}$ (titre) of $\mathrm{NaOH}$ from methoxyl content determination, $\mathrm{W}=$ weight of pectin sample.

Determination of degree of esterification. The pectin degree of esterification (DE) was determined by titrimetric method described by Bello et al. (2008), with minor modifications, as explained below: $0.2 \mathrm{~g}$ of dried pectin was weighed and transferred into a $250 \mathrm{~mL}$ Erlenmeyer flask; and then moistened with $5 \mathrm{~mL}$ of ethanol and dispersed in $20 \mathrm{~mL}$ of distilled water at 40 ${ }^{\circ} \mathrm{C}$ under continuous stirring at $700 \mathrm{rpm}$ for $2 \mathrm{~h}$. Then $10 \mathrm{~mL}$ of the dispersed pectin was transferred into a $100 \mathrm{~mL}$ volumetric flask and the volume was adjusted with distilled water. An aliquot $(20 \mathrm{~mL})$ was taken and transferred into a $250 \mathrm{~mL}$ Erlenmeyer flask. The aliquot was titrated against sodium hydroxide $(0.1 \mathrm{M})$ in the presence of three drops of phenolphthalein solution and the result was recorded as (V1). Then, $10 \mathrm{~mL}$ of sodium hydroxide $(0.1 \mathrm{M})$ was added and the solution was stirred at $300 \mathrm{rpm}$ at room temperature for $2 \mathrm{~h}$. After that $10 \mathrm{~mL}$ hydrochloric acid $(0.1 \mathrm{M})$ was added and hand-shaken until the pink color disappeared, then three drops of phenolphthalein solution were added and the solution was titrated against sodium hydroxide $(0.1 \mathrm{M})$ and the result was recorded $\left(\mathrm{V}_{2}\right)$. The degree of esterification (DE) can be calculated using the following equation:

$$
\mathrm{DE}(\%)=\frac{\mathrm{V}_{2}}{\mathrm{~V}_{1}+\mathrm{V}_{2}} \times 100
$$

where:

$\mathrm{V}_{1}=$ volume $\left(\mathrm{cm}^{3}\right)$ of sodium hydroxide $(0.1 \mathrm{M})$ used in first titration, and $\mathrm{V}_{2}=$ volume $\left(\mathrm{cm}^{3}\right)$ of sodium hydroxide $(0.1 \mathrm{M})$ used in second titration.

FTIR analysis. The infra-red (IR) analysis of the extract was carried out using infra-red spectrophotometer (Buck Scientific Inc, CT USA, Model M500) between 600 to $4000 \mathrm{~cm}^{-1}$.

Swelling studies of pectin samples. The swelling studies of the extracted pectin samples were carried out in deionized water by gravimetric method. About $2.0 \mathrm{~g}$ of the extracted pectin sample was weighed and immersed in excess water in a beaker for $30 \mathrm{~min}$ for different time intervals at $37{ }^{\circ} \mathrm{C}$ and then the samples were removed, wiped with tissue paper to remove excess of solvent, and then weighed immediately. The difference in weight was calculated to obtain the weight gain at different time intervals (Singh and Lee, 2014). The percentage swelling was calculated from the expression below:

$$
\text { Swelling ratio }(\%)=\frac{\mathrm{W}_{\mathrm{t}}-\mathrm{W}_{\mathrm{d}}}{\mathrm{W}_{\mathrm{d}}} \times 100
$$

where:

$\mathrm{W}_{\mathrm{t}}$ is the weight of the swollen pectin at time, $\mathrm{t}$ and $\mathrm{W}_{\mathrm{d}}$ is the initial weight of the dried pectin before immersion.

\section{Results and Discussion}

Yield of extracted pectin. The percentage yield of the extracted pectin from Bombax ceiba fruits under the varying experimental conditions of temperature, extraction time and $\mathrm{pH}$ are given in Table 1.

Table 1. Pectin yield of Bombax ceiba fruits obtained at extraction $\mathrm{pH} 2.0$ under varying extraction temperature and time, followed by precipitation with $96 \%$ ethanol

\begin{tabular}{lll}
\hline \hline Time (mins) & Temperature $\left({ }^{\circ} \mathrm{C}\right)$ & Pectin yield $(\% \mathrm{w} / \mathrm{w})$ \\
\hline 45 & 70 & 4.55 \\
60 & & 6.78 \\
90 & & 9.35 \\
45 & 85 & 11.67 \\
60 & & 14.75 \\
90 & & 16.35 \\
45 & 105 & 14.85 \\
60 & & 13.36 \\
90 & & 10.78 \\
\hline \hline
\end{tabular}

Effect of extraction process parameters on pectin yield. Effects of temperature on pectin extraction yield. As shown in Fig. 1 the pectin yield is greatly influenced by temperature. The yield increases significantly with the increasing temperature for Bombax ceiba fruits sample until the temperature was above $85^{\circ} \mathrm{C}$. Increasing the extraction temperature would increase the solubility of the extracted pectin, giving a higher rate of extraction. However, a further increase in temperature from 85 to $105{ }^{\circ} \mathrm{C}$ shows a declining tendency of pectin yield, since too high temperature would lead to breaking of pectin molecules as pectin is composed of $\alpha-(1-4)$ linked units of galacturonic acid or methyl ester resulting in pectin of lower molecular size which is not stable and 
extractable with ethanol and consequently, the pectin yield declined. Also, high temperature encourages energy loss through vaporization and increases the cost of extraction process from the industrial point of view. At lower temperature, the lower viscosity of pectin might cause poor diffusion between the phases that could cause a slower rate of extraction leading to a low yield of pectin.

From the previous research works, it was shown that temperature; extraction time and $\mathrm{pH}$ had a notable influence on the pectin yields. This is why these conditions were chosen and monitored. Thus, the results obtained were similar and agreed with those obtained by Udonne et al. (2016). Based on the current literatures (Udonne et al., 2016; Ania et al., 2012; Dodi et al., 2011), it could be seen that low $\mathrm{pH}$ gives high pectin yield, although it also depends on the plant materials this is why a low $\mathrm{pH}$ of 2.0 was chosen for this research work while other parameters were varied.

Effect of extraction time on the pectin yield. From the results shown in Fig. 2, the pectin yield was observed to have increased significantly with the increase in the extraction time. It is clear that the yield of pectin increases up to $90 \mathrm{~min}$ and thereafter it starts declining. This may be due to the fact that a relatively long period of extraction would cause a thermal degradation on the extracted pectin, thus causing a decrease in the amount extractable by the alcohol during the precipitation process. Apart from that, the colour of the pectin extract became dark red for longer periods of extraction which invariably required a higher number of alcoholic washing of the precipitate. Also as the extraction proceeds, the concentration of the pectin in the solution will increase and

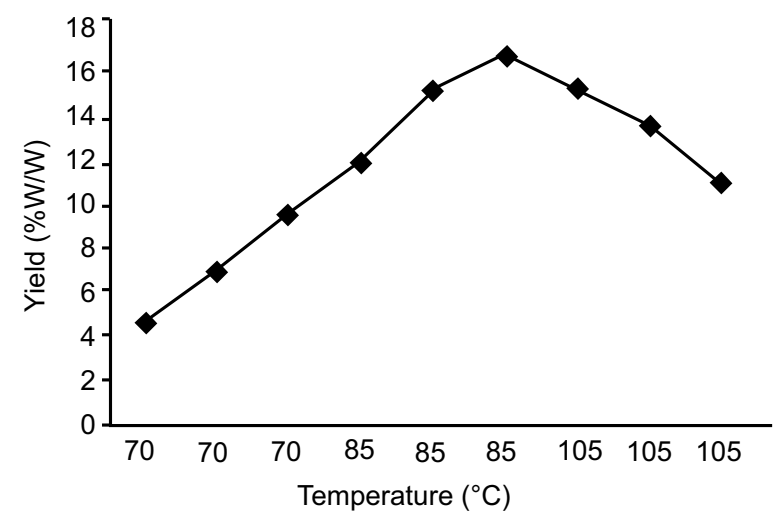

Fig. 1. Effect of extraction temperature on the pectin yield. the rate of extraction will also progressively decrease; due to fact that the concentration gradient will be reduced and, consequently, the solution becomes more viscous. Generally, the result shows that the yield increases with an increase in extraction time as the proto-pectin naturally present in cells take time to solubilize and go into the solution. However, at longer extraction time and higher temperatures, the pectin with an increase begins to decline. This probably could be due to hydrogen bond dissociation as a result of thermal degradation of pectin backbone that may likely occur at high temperatures (Vriesmann et al., 2012).

From this current work, the optimum pectin yield was obtained at a temperature of $85{ }^{\circ} \mathrm{C}$ and extraction time of $90 \mathrm{~min}$ as $16.35 \%$ extracts as given in Table 1 .

Physicochemical characterization of pectin. Qualitative test of extracted pectin. The qualitative test results for the sample are given in Table 2. It was observed that in cold water, the pectic sample was insoluble but dissolved slightly and forms suspension after vigorous shaking for about $15 \mathrm{~min}$. However, when the temperature was raised to $85^{\circ} \mathrm{C}$, the solubility was gradually increased. The results obtained in this research work shows a similar characteristic with that of earlier researchers as reported by Udonne et al. (2016) and that of Fishman (1993), which stated that pectin is unstable under alkaline solution. This agrees with the results obtained from this work.

Quantitative analysis of the extracted pectin. Physicochemical characterizations. Physicochemical Characterizations of the extracted pectin were carried out for various parameters in order to evaluate its suitability in

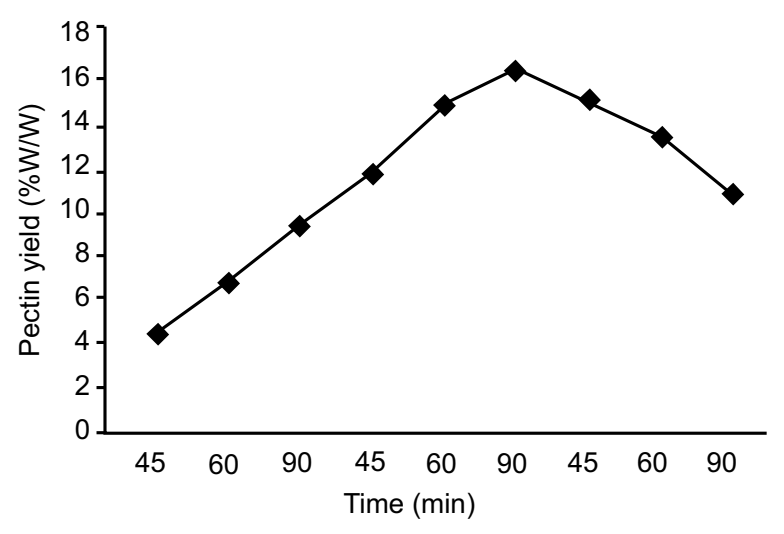

Fig. 2. Effect of extraction time on the pectin yield. 
industrial applications. The extraction time and $\mathrm{pH}$ had a significant effect on the degree of esterification and moisture content of all the samples. The physicochemical characterizations of pectin depend mainly on the raw material source and conditions selected for isolation and purification. Table 3 gives a brief summary of the parameters that were determined in other to evaluate the physicochemical quality characteristics of Bombax ceiba fruits pectin. The value of equivalent weight of Bombax ceiba fruits extracted pectin was found to be $765.40 \mathrm{~g} / \mathrm{mL}$. The methoxyl content is an important factor in controlling the setting time of pectin and the ability of the pectin to form gels (Ania et al., 2012). The value of the methoxyl content obtained was $6.62 \%$ which is within the range, from previous study literature had it that methoxyl content of extracted pectin varies from $0.2-12 \%$ depending on the source and mode of

Table 2. Quantitative test for pectin extracted at $85^{\circ} \mathrm{C}$, pH 2.0 and 90 min extraction time

\begin{tabular}{ll}
\hline \hline Parameter & Pectin samples \\
\hline $\begin{array}{l}\text { Solubility in cold water } \\
\text { Solubility in water at } \\
85{ }^{\circ} \mathrm{C} \text { for } 15 \mathrm{~min}\end{array}$ & $\begin{array}{l}\text { Insoluble, forms suspension after } \\
\text { vigorous shaking, The mixture } \\
\text { dissolved gradually }\end{array}$ \\
$\begin{array}{l}\text { Solubility of pectin } \\
\text { solution in cold alkali } \\
(\mathrm{NaOH}) 0.1 \mathrm{M}\end{array}$ & A reddish precipitate was formed \\
$\begin{array}{l}\text { Solubility of pectin } \\
\text { solution in hot alkali } \\
\text { (NaOH, 0.1 M) at } 40{ }^{\circ} \mathrm{C}\end{array}$ & The reddish precipitate dissolved \\
for 10 mins & \\
Colour & Yellowish Brown milky \\
\hline \hline
\end{tabular}

Table 3. Physicochemical composition of the extracted pectin under optimum conditions of $85^{\circ} \mathrm{C}, 90 \mathrm{~min}$ and $\mathrm{pH} 2.0$

\begin{tabular}{ll}
\hline \hline Composition & Pectin samples \\
\hline Yield of pectin $(\% \mathrm{w} / \mathrm{w})$ & 16.35 \\
Moisture content $(\% \mathrm{w} / \mathrm{w})$ & 1.30 \\
Ash content $(\% \mathrm{w} / \mathrm{w})$ & 0.60 \\
Equivalent weight $(\mathrm{g} / \mathrm{mL})$ & 765.40 \\
Methoxyl content $(\%)$ & 6.45 \\
Anhydrouronic acid (\% AUA) Degree & 65.25 \\
Degree of esterification (\% DE) & 73.80 \\
$\mathrm{pH}$ & 3.68 \\
\hline \hline
\end{tabular}

extraction. Since the value obtained experimentally is below $7.5 \%$, hence the pectin was of low ester content, which is a characteristic indicatiion that the pectin obtained is good in terms of quality (Jafar and Gisoo, 2012). The degree of methylation and pectin yield are important factors in determining the firmness of the gel and, subsequently, the value and possible use of raw material in the food industry and other applications.

Extraction that aims to obtain a higher yield and better characteristic properties of pectin in terms of degree of methylation is a useful tool for technological purposes. The moisture and ash content of 1.30 and $0.60(\% \mathrm{w} / \mathrm{w})$, respectively were obtained in this extracting conditions. The results showed that pectin samples have minimal moisture content and low ash content which is very important factor required for checking quality of pectin for both utilization and storage. Anhydrouronic acid content and degree of esterification in the samples were found to be 65.25 and $67.80 \%$, respectively. According to FAO, the content of galacturonide expressed as galacturonic acid, C6H10O7 (MW 194.1) must be at least $65 \%$ on sugar, ash, and moisture free basis.

The anhydrouronic acid (AUA) indicates the purity of the extracted pectin and its value should not be less than $65 \%$ as reported by NAS (1996). In this study, the AUA content of Bombax ceiba fruit pectin was within the acceptable limits of pectin purity. Although it falls within the value of high methoxyl pectin, based on $\mathrm{DE}$ pectin can be classified as low methoxyl pectin with = $50 \% \mathrm{DE}$ and high methoxyl pectin with $>50 \% \mathrm{DE}$. Therefore, this study indicates that extracted pectin can be categorized as high methoxyl pectin. Low moisture content is required for pectin for safe storage as well as to inhibit the growth of microorganisms that can affect the quality due to the production of pectinase enzymes. The moisture content of the pectin is almost similar to the values of moisture content reported in the literature. The ash content of the extracted pectin was found to be $0.60 \%$. The upper limit of ash content for good-quality pectin is considered to be $10 \%$ from the viewpoint of gel-formation (Udonne et al., 2016).

Gel-setting time is a function of DE, with rapid-set pectin possessing a DE of 72 to $75 \%$, medium-set pectin a DE of 68 to 71, and slow-set pectin a DE of 62 to 66\% (Crandall and Wicker, 1986). Such distinctions are of value in processing where speeds of gelatin can influence product quality. Rapid-set pectin is useful in the manufacture of jams and ensure a uniform dispersal 
of fruit pieces and prevent floating. When flotation of fruit is not a problem, such as in clear jellies, then slowset pectin are preferable because they allow entrained air bubbles to rise before gelatin. Esterification levels of pectin can also have an effect on the amour perception of jellies. From the above, it can be observed that the pectin obtained in this analysis is HM pectin with rapidset pectin based on the value of DE obtained is above $70 \%$.

Therefore, with respect to this parameter, the pectin extracted in this study may be considered to be of satisfactorily good quality. The inorganic impurities in pectin were indicated by the ash content. Lower ash content indicates good quality of pectin. The ash content of extracted pectin was close to the reported values by other researchers.

FTIR spectroscopy of extracted pectin. The FTIR spectra of extracted pectin from the fruits of Bombax ceiba is presented in Fig. 3. It could be seen that the peak at $3282.92 \mathrm{~cm}^{-1}$ is likely due to $\mathrm{O}-\mathrm{H}$ stretching vibration, $2931.09 \mathrm{~cm}^{-1}$ is due to $\mathrm{sp}^{3} \mathrm{C}-\mathrm{H}, 1613.93 \mathrm{~cm}^{-1}$ through $1737.45 \mathrm{~cm}^{-1}$ is due to $\mathrm{C}=\mathrm{O}$ stretching vibration, $1448.79 \mathrm{~cm}^{-1}$ is due to $\mathrm{sp}^{3} \mathrm{CH}_{2}$ bending of methylene bridge, $1367.18 \mathrm{~cm}^{-1}$ through $1113.88 \mathrm{~cm}^{-1}$ is due to $\mathrm{C}-\mathrm{O}$ stretching vibration and $867.11 \mathrm{~cm}^{-1}$ is due to $\mathrm{sp}^{2}$ $\mathrm{C}-\mathrm{H}$ bending vibrations. The FTIR spectra showed a good match with the spectrum of commercial pectin. According to Gnanasambandam and Proctor (2000), a small difference in the structure and composition of a molecule can result in significant changes in the absorption peaks.

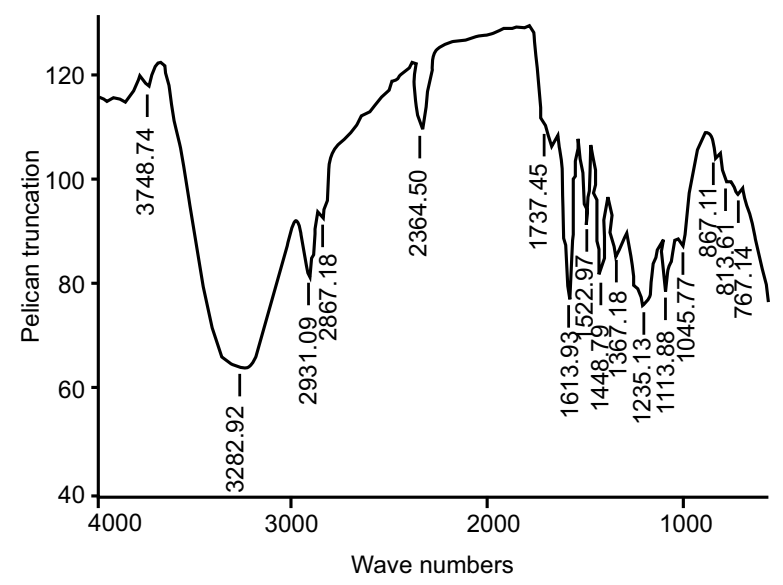

Fig. 3. FTIR spectra of pectin extracted from Bombax ceiba.
The FTIR spectra in the region between 4000-400 $\mathrm{cm}^{-1}$ identified the major chemical groups such as $\mathrm{OH}$, $\mathrm{COOH}, \mathrm{ad} \mathrm{COOCH}_{3}$ in the pectin and provided structural information of pectin molecule. The spectral data obtained was analyzed by comparing the FTIR spectra in the following characteristic regions. O-H stretching band envelope $3748.74-3282.92 \mathrm{~cm}^{-1}$, C-H stretching bands $3000-2800 \mathrm{~cm}^{-1}$, the fingerprint region of spectra under $2000 \mathrm{~cm}^{-1}$, including the band contributing to resonant absorption energy of pyranose cycle vibrations $1448.39-767.14 \mathrm{~cm}^{-1}$, as well as the region 1113.88 $1653.54 \mathrm{~cm}^{-1}$ featuring the state of carboxylic groups. For the pyranose cycle vibrations region, one should note almost identical spectral parts with bands at 1653.54 , $1430.65,1110.11,1010.09$ and $890.28 \mathrm{~cm}^{-1}$ characteristic for peptic substances.

The region that characterizes the state of carboxylic groups can be observed (approx. 1731.45-1350 $\mathrm{cm}^{-1}$ ) (Filipov, 1992). The band at approximately 1731.45 $\mathrm{cm}^{-1}$ is indicative of the stretching group $\mathrm{C}=\mathrm{O}$ of nonionized carboxylic acid (methylated or protonated). Its ionization (formation of salt) leads to their disappearance, and the appearance of stretch modes of COO- in approximately $1600-1650$ and $1400-1450 \mathrm{~cm}^{-1}$, respectively (Filipov, 1992). The degree of methylation (DM) is defined as the percentage of ester groups compared to the total number of acid groups and carboxylic ester and it is observed that the high intensity of the band at $1731.45 \mathrm{~cm}^{-1}$ shows that the pectin obtained is of high degree of methylation.

Thus, in principle, considering the relative intensities of bands in these regions, one may correlate them to the relative amount and degree of esterification of carboxylic groups of the spectra given in Fig. 3. The absorption peaks are closely related; therefore, it can generally be interpreted thus; the absorption bands between $1235.49-1103.21 \mathrm{~cm}^{-1}$ were likely to be from ether (R-O-R) and ring $\mathrm{C}-\mathrm{C}$ bonds in pectin molecules. The polysaccharides that contributed to this distinction are the peptic polysaccharides rich in galacturonic acid and Xylose that contains hemicellulosic polysaccharides. The selection of the most important wave numbers, by two independent chemometric techniques allowed for defining the regions of $1100-800 \mathrm{~cm}^{-1}$ as the range for the spectral identification of galacturonic acid in peptic polysaccharides. The band centered at $1743.49 \mathrm{~cm}^{-1}$ has been utilized to probe the $\mathrm{DE}$ in pectin. This band can be assigned to the $\mathrm{C}=\mathrm{O}$ stretching vibration of methyl ester. The bands in the Bombax ceiba pectin 
spectrum are within this region, a major absorption peak between $1617 \mathrm{~cm}^{-1}$ and $1384 \mathrm{~cm}^{-1}$. These two bands correspond, respectively, to asymmetrical and symmetrical stretching vibrations due to the COOgroup of polygalacturonic acid. The absorbance at 1200 and $1100 \mathrm{~cm}^{-1}$ are the anhydrouronic acid, because all peptic polysaccharides characterized mainly by these peaks. Therefore, it is imperative to say that, the pectin polysaccharide extracted from these fruits shows the content of the pectin molecule when compared with the standard spectra of the pectin molecule.

Swelling studies of pectin sample. Pectin is soluble in water but not in organic solvents (Liu et al., 2006). Therefore, the swelling study was conducted in water. The presence of carboxylic acid groups makes pectin a polyelectrolyte and a weak organic acid. When pectin is added to water, carboxylic acid groups dissociate and the pectin molecules become negatively charged. Solubility is increased by all factors diminishing possibilities of intermolecular association (Thibault and Ralet, 2001).

From the results obtained, in Table 4, it showed that the pectin swelling increases with increasing temperatures as seen in Fig. 4. The swelling value at $60^{\circ} \mathrm{C}$ is twice as big as the value at $30{ }^{\circ} \mathrm{C}$. It is possible to suggest that the $\mathrm{H}$-bonds inside the pectin sample were

Table 4. Swelling studies of the pectin extracted at $85{ }^{\circ} \mathrm{C}$ for $90 \mathrm{~min}$ in $\mathrm{DH}_{2} \mathrm{O}$ at a temperature of $30^{\circ} \mathrm{C}$ maintain in a water bath at varying time intervals of 30 $\min$

\begin{tabular}{ll}
\hline \hline Swelling time $(\mathrm{min})$ & Swelling ratio $(\% \mathrm{w} / \mathrm{w})$ \\
\hline 0.00 & 0.00 \\
30.00 & 6.30 \\
60.00 & 7.80 \\
90.00 & 11.60 \\
120.00 & 14.70 \\
150.00 & 17.10 \\
180.00 & 25.50 \\
210.00 & 35.90 \\
240.00 & 42.10 \\
270.00 & 50.30 \\
300.00 & 50.10 \\
\hline
\end{tabular}

The swelling studies of the pectin extracted at $85^{\circ} \mathrm{C}$ for 90 min in $\mathrm{DH}_{2} \mathrm{O}$ at a temperature of $30^{\circ} \mathrm{C}$ maintain in a water bath at varying time intervals of $30 \mathrm{~min}$ is shown in Fig. 4. As the time of extraction increases, there is an increase in the swelling ratio of the hydrogel and became stable at $240 \mathrm{~min}$.

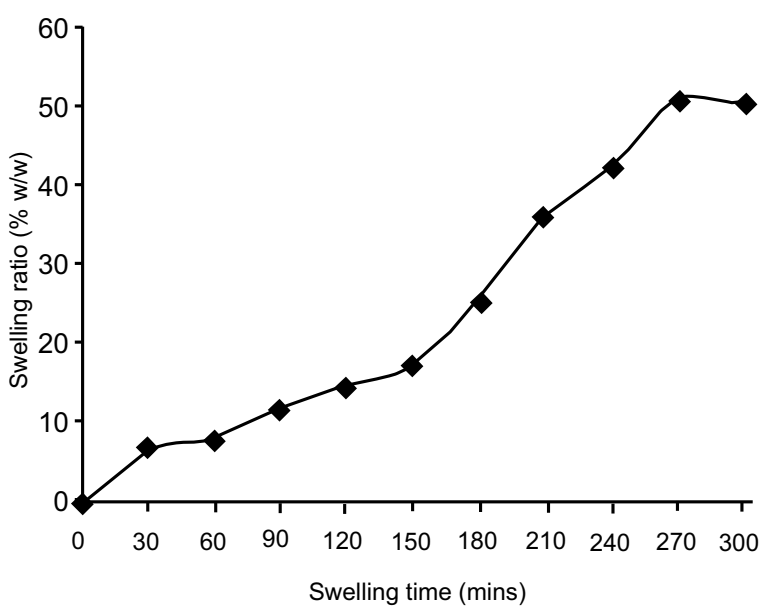

Fig. 4. Swelling studies of the pectin extracted at $85^{\circ} \mathrm{C}$ for $90 \mathrm{~min}$ in $\mathrm{DH}_{2} \mathrm{O}$ at a temperature of $30^{\circ} \mathrm{C}$.

broken due to temperature rise and thus increase the amount of swelling. Also, the increase in swelling value with increasing temperature of the pectin might be caused by the increase in thermal mobility of polymer molecules inside the pectic substance (Nanasombat et al., 2012).

\section{Conclusion}

The procedure for extracting fruit pectin from Bombax ceiba was optimized in terms of $\mathrm{pH}$, extraction time and temperature, thus allowing the most efficient and suitable, in terms of yield and degree of esterification, to be chosen. The degree of esterification is an important factor in determining the possible use of raw material in the food industry. Esterification levels of pectin can also have an effect on the amour perception of jellies. From the above, it can be observed that the pectin obtained in this analysis is HM pectin with rapid-set pectin based on the value of $\mathrm{DE}$ obtained is above $70 \%$. The pectin obtained was of low ester content, which is a characteristic indicating that the pectin obtained is good in terms of quality (Jafar and Gisoo, 2012) and can find several applications industrially.

\section{Acknowledgement}

The authors are grateful to Chemistry Department Modibbo Adama University of Technology Yola for providing the infrastructural facilities. The authors also wish to thank Dr. O.N. Maitera and Mrs. P.M. Owuama for their valuable assistance in the direction of the completion of this research work. 
Conflict of Interest. The authors declare no conflict of interest.

\section{Reference}

AOAC, 1995. Official Methods of Analysis, $16^{\text {th }}$ edition, Association of Official Analytical Chemists, Washington DC, USA.

Ania, V.O., Barau, M.M., Mamman, O.A., Zakari, A., Hauwa, H., Hauwa, M.S.U., Yagana, B.A. 2012. Extraction and characterization of pectin from peels of lemon (Citrus lemon), grape fruit (Citrus paradisi) and sweet orange(Citrus sinensis). British Journal of Pharmacology and Toxicology, 3: 259-262.

Crandall, P.G., Wicker, L. 1986. Pectin internal gel strength: Theory, measurement and methodology. ACS Symposium Series, vol. 310, pp. 88-102, ACS Publications American Chemical Society, Washington, DC, USA.

Desai, K.G.H. 2005. Preparation and characteristics of high-amylose corn starch/pectin blend microparticles: A Technical note. AAPS Pharmaceutical Science Technology, 6: E202-E208.

Dodi, G., Hritcu, D., Popa, M.I. 2011. Carboxymethylation of guar gum: Synthesis and characterization. Cellulose Chemistry and Technology, 3: 171-176.

Filipov, M.P. 1992. Practical infrared spectroscopy of pectic substances. Food Hydrocolloids, 6: 115-118.

Fishman, M.L., Coffin, D.R. 1993. Films fabricated from mixtrues of pectin and starch. United States Patent 5, 451, 673A.

Gnanasambandam, R.P., Octor, A. 2000. Determination of pectin degree of esterification by diffuse reflectance Fourier Transform Infrared Spectroscopy. Food Chemistry, 68: 327-332.

Jafar, M., Gisso, M. 2012. Hydrocolloids in Food Industry. Available online: www.researchgate.net/ publication/221925367. Retrieved on: 27 September, 2016. DOI: $10.5772 / 32358$

Joslyn, M.N. 1980. Methods of Food Analysis, Physical Chemical and Instrumentation Method of Analysis. $2^{\text {nd }}$ edition, vol. 5, pp. 67-70, Academic Press, New York, USA.

Khule, R.N., Nitih, B.M., Dipak, S.S., Manisha, M.R., Sanjay, R.C. 2012. Extraction of pectin from citrus fruits peel and use as natural binder in paracetamol tablet. Der Pharmacia Lettre, 4: 558-564.

Kulkarni, S.G., Vijayanand, P. 2010. Effect of extraction conditions on the quality characteristics of pectin from passion fruit peel (Passiflora edulis F. flavicarpa L.). LWT-Food Science and Technology,
43: 1026-1031.

Liu, Y., Shi, J., Langrish, T.A.G. 2006. Water-based extraction of pectin from flavedo and albedo of orange peels. Chemical Engineering Journal, 120: 203-209.

Liu, P., Zhai, M., Li, J., Peng, J., Wu, J. 2002. Radiation preparation and swelling behavior of sodium carboxymethyl cellulose hydrogels. Radiation Physics and Chemistry, 63: 525-528.

Lúcia, C.V., Reinaldo, F.T., Carmen, L.O.P. 2012. Extraction and characterization of pectin from cacao pod husks (Theobroma cacao L.) with citric acid. LWT-Food Science and Technology, 49: 108116.

Malviya, R., Srivastava, P., Kulkarni, G.T. 2011. Application of mucilages in drug delivery-A review. Advances in Biological Research, 5: 1-7.

Menon, S.S., Basavaraj, B.V., Bharath, S., Deveswaran, R., Madhavan, V. 2011. Formulation and evaluation of Ibuprofen tablets using orange peel pectin as binding agent. Der Pharmacia Lettre, 3: 241-247.

Minjares-Fuentas, R., Femenia, A., Garau, M.C., MezaVelazquez, J.A., Simal, S., Rossello, C. 2014. Ultrasound-assisted extraction of pectins from grape pomace using citric acid: A response surface methodology approach. Carbohydrate Polymers, 106: 179-189.

Nanasombat, S., Khanha, K., Phan-im, J., Jitaied, J., Wannasomboon, S., Patradisakorn, S., Wongsil, A. 2012. Antimicrobial and antioxidant activities of Thai local fruit extracts: application of a selected fruit extract, Phyllanthus emblica Linn. as a natural preservative in raw ground pork during refrigerated storage. TOJSAT The Online Journal of Science Technology, 2: 1-7.

NAS, 1996. Food Chemical Codex V. National Academy of Sciences, pp. 283-286, $4^{\text {th }}$ edition, National Acdemy Press, Washington DC, USA.

Pinheiro, E.R., Silva, I.M.D.A., Gonzaga, L.V., Amante, E.R., Teófilo, R.F., Ferreira, M.M.C., Amboni, R.D.M.C. 2008. Optimization of extraction of highester pectin from passion fruit peel (Passiflora edulis Flavicarpa) with citric acid by using response surface methodology. Bioresourse Technology, 99: 5561-5566.

Santos, J.D.G., Espeleta, A.F., Branco, A., de Assis, S.A. 2013. Aqueous extraction of pectin from sisal waste. Carbohydrate Polymer, 92: 1997-2001.

Singh, N.K., Lee, D.S. 2014. In situ gelling pH- and temperature-sensitive biodegradable block copolymer 
hydrogels for drug delivery. Journal of Control Release, 193: 214-227.

Sriamornsak, P. 2003. Chemistry of pectin and its pharmaceutical uses: A review. Silpakorn University International Journal, 3: 206-228.

Srivastava, P., Rishabha, M. 2011. Sources of pectin, extraction and its applications in pharmaceutical industry - An overview. Indian Journal of Natural Products and Resources, 2: 10-18.

Srivastava, P., Malviya, R., Kulkarni, G.T. 2010. Formulation and evaluation of Paracetamol tablets to assess binding property of orange peel pectin. International Journal of Pharmaceutical Sciences, Review and Research, 3: 30-34.

Tang, P.I.Y., Wong, C. J., Woo, K.K. 2011. Optimization of pectin extraction from peel of dragon fruit (Hylocereus polyrhizus). Asian Journal of Biological Sciences, 4: 189-195.

Thibault, J.-F., Ralet, M.-C. 2001. Pectins, Their Origin,
Structure and Function. In: Advanced Dietary Fibre Technology, McCleary, B.V., Prosky, L. (eds), pp. 369-378, Blackwell Science, London, UK.

Udonne, J.D., Ajani, O.O., Akinyemi, O.P. 2016. A Comparative Study of Extraction of Pectin from Wet and Dried Peels Using Water Based and Microwave Method. International Journal of Science and Engineering Research, 7: 416-432.

Vriesmann, L.C., Teofilo, R.F., Petkowicz, C.L.D. 2012. Extraction and characterization of pectin from cacao pod husks (Theobroma cacao L.) with citric kid. LWT-Food Science and Technology, 49: 108116.

Yang, D., Zhang, J.Z., Fu, S., Xue, Y., Hu, J. 2009. Evolution process of polymethacrylate hydrogels investigated by rheological and dynamic light scattering techniques. Colloids and Surfaces A: Physicochemical and Engineering Aspects, 353: 197-203. 